\title{
Backstepping Predictive Control of Hybrid Microgrids Interconnected by Neutral Point Clamped Converters
}

\author{
J. Dionísio Barros ${ }^{1,2}\left(\mathbb{D}\right.$, Luis Rocha ${ }^{2,3, *(\mathbb{D})}$ and J. Fernando Silva ${ }^{2,4}(\mathbb{D}$ \\ 1 Departamento de Engenharia Eletrotécnica, Faculdade de Ciências Exatas e da Engenharia, \\ Campus Universitário da Penteada, Universidade da Madeira, 9020-105 Funchal, Portugal; dbarros@uma.pt \\ 2 INESC-ID, 1000-029 Lisboa, Portugal; fernando.alves@tecnico.ulisboa.pt \\ 3 Instituto Superior de Engenharia de Lisboa, Polytechnic Institute of Lisbon, 1959-007 Lisbon, Portugal \\ 4 Instituto Superior Técnico, University of Lisbon, 1049-001 Lisbon, Portugal \\ * Correspondence: luisrocha@deea.isel.ipl.pt
}

check for updates

Citation: Barros, J.D.; Rocha, L.; Silva, J.F. Backstepping Predictive Control of Hybrid Microgrids Interconnected by Neutral Point Clamped Converters. Electronics 2021, 10, 1210. https://doi.org/10.3390/ electronics10101210

\section{Academic Editors: Md}

Enamul Haque, Sajeeb Saha and Jiefeng $\mathrm{Hu}$

\section{Received: 14 April 2021}

Accepted: 16 May 2021

Published: 19 May 2021

Publisher's Note: MDPI stays neutral with regard to jurisdictional claims in published maps and institutional affiliations.

Copyright: (c) 2021 by the authors. Licensee MDPI, Basel, Switzerland. This article is an open access article distributed under the terms and conditions of the Creative Commons Attribution (CC BY) license (https:/ / creativecommons.org/licenses/by/ $4.0 /)$.

\begin{abstract}
In this work, DC and AC parts of hybrid microgrids are interconnected by a neutral point clamped-NPC converter controlled using a new backstepping predictive (BP) method. The NPC converter is controlled to operate in the DC microgrid voltage control mode or in the AC microgrid power control mode. The novel backstepping predictive controller is designed using the $d q$ state space dynamic model of the NPC converter connected to the hybrid microgrid. The designed BP controller regulates the DC voltage or AC injected power, balances the capacitor voltages, controls the AC currents, and enforces the near unity power factor. Simulation (MATLAB/Simulink) and experimental (laboratory prototype) results show that the converter can regulate the DC voltage in the DC microgrid interconnection point, by adjusting the $\mathrm{AC}$ power conversion to compensate variations on the loads or on the distributed renewable energy sources in the DC microgrid. AC currents are sinusoidal with low harmonic distortion. The obtained BP controller is faster at balancing capacitor voltages than PWM (pulse width modulation) control with carrier offset. The fast AC power response allows the converter to be used as a primary frequency regulator of the AC microgrid. This research is appropriate for power and voltage control in hybrid microgrids with renewable energy.
\end{abstract}

Keywords: microgrids; backstepping; backstepping predictive; hybrid; multilevel converter; capacitor voltage balance

\section{Introduction}

In recent years much progress has been made in microgrids $(A C, D C$, and hybrid $\mathrm{AC} / \mathrm{DC}$ ) as they allow easier integration of both renewable energy resources and energy storage systems in the electrical power grids [1-4].

Microgrids are local grids formed by distributed generation (DG) such as renewable energies (wind and photovoltaic (PV) energy), non-renewable energies (diesel and fuel generators), electric energy storage (EES), and loads [5-7]. A typical structure of an AC microgrid $[4,5]$ is depicted in Figure $1[6,8,9]$.

Most DGs are interfaced to microgrids through switching converters (AC/DC, DC/DC, or $\mathrm{DC} / \mathrm{AC}$ ) and must have the capability to operate in either one of two modes: connected to AC large scale grid (Figure 1 switch ON) or in the islanded mode (Figure 1 switch OFF), when the microgrid is operated separated from the grid [4-6,8,10-12].

DG systems have advantages over conventional generators due to the high level of controllability and operability (increasing the stability in the electrical systems). One important advantage of microgrids is the improvement of supply reliability for consumers, although there are some difficulties in the standardized equipment $[5,13,14]$.

There is already some regulation for the interconnection of DGs to the grid and in case of failure the disconnection from the grid is required. However most DGs are not ready 
to be directly connected to AC grids, needing power electronic converters to enable their integration $[3,5,15]$.

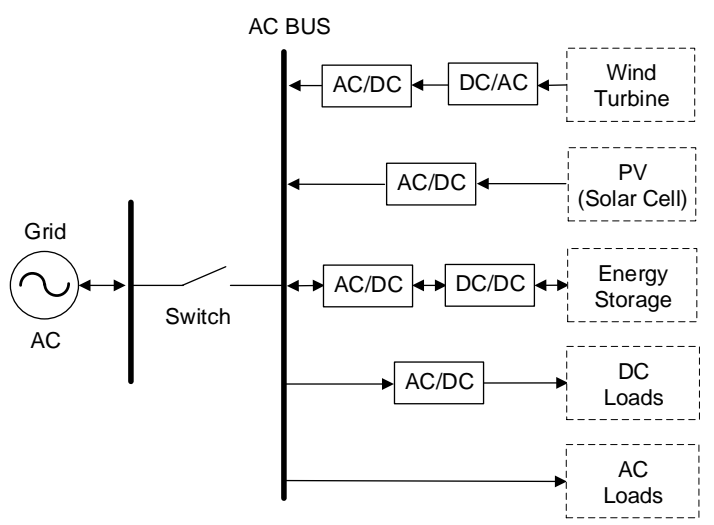

Figure 1. Typical configuration of an AC microgrid.

Modern electronic loads are DC operated and PV panels generate DC power, therefore for efficiency it is advisable to connect electronic loads and PV panels directly to a DC bus (DC microgrid), through DC-to-DC converters (AC/DC conversion is no longer necessary). The coordination of these $\mathrm{DC}$ microgrids is easier in comparison with $\mathrm{AC}$ microgrids requiring simpler management algorithms. One big advantage of DC microgrids regarding AC microgrids is the absence of reactive power and harmonics, thus increasing the electric power quality. Another advantage of DC microgrids over AC microgrids is the reduction of conversion losses of inverters between the DC sources and loads. A typical structure of a DC microgrid is represented in Figure 2 [1,16-20].

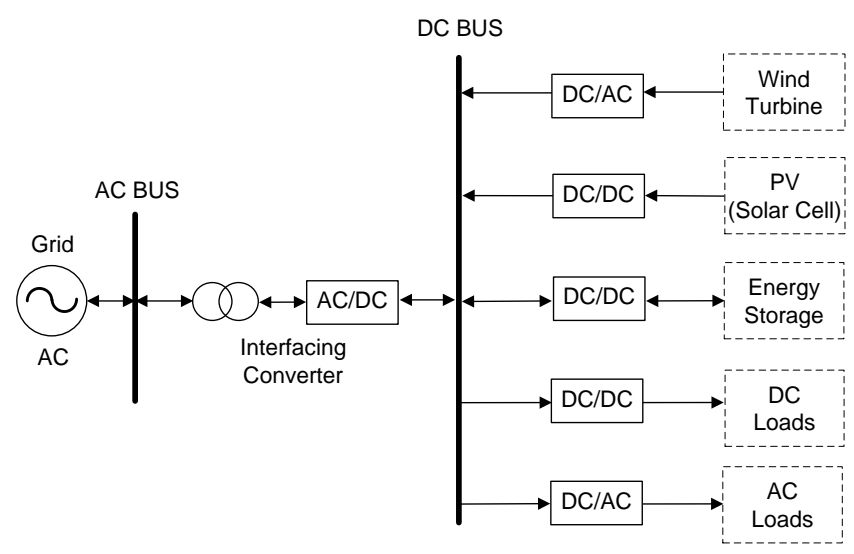

Figure 2. Typical configuration of a DC microgrid.

The recently emerged hybrid AC/DC microgrid combines the advantages of both DC and $\mathrm{AC}$ systems. Hybrid microgrids have been proposed to replace existing ones (AC or $\mathrm{DC}$ ) in order to reduce multiple AC-DC-AC or DC-AC-DC conversions to individual AC or DC microgrids. Additionally, in this topology there are two possible operation modes: microgrid connected to the grid and microgrid in islanded mode. This new topology (hybrid AC/DC microgrid) can simplify the integration process of DC power technologies into existing $\mathrm{AC}$ systems and vice-versa. Figure 3 shows a typical structure of a hybrid AC/DC microgrid [4,13,14,21-24].

Multilevel converters enable high power and voltage processing using relatively low hold-off voltage semiconductors. In hybrid microgrids the power control should be bidirectional and harmonic distortion must show low values [25-29]. Among the most common multilevel converter are the neutral point clamped (NPC) converter [30], the flying-capacitors 
converter [31], and the cascaded multicell with separate DC sources [32]. The predictive control method has been used to control multilevel converters and sinusoidal pulse width modulation (PWM), sliding mode, and space-vector modulation (SVM) [33-37].

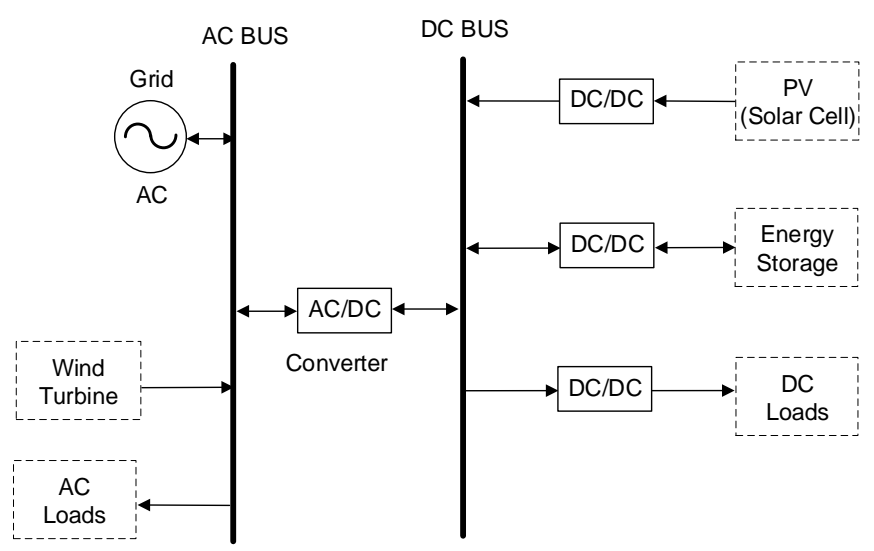

Figure 3. Typical configuration of a hybrid AC/DC microgrid.

A control method that improves the droop control for DC microgrids is described in [1]. It takes into account the line resistance in the droop control and dc-bus voltage deviation increases with increasing load power, using a distributed control. However, this control method assumes the power converter as a linear system, neglecting also the converter dynamics. Therefore, in this work, the microgrid DC voltage control is developed considering the NPC converter non-linear dynamic model. A modified backstepping control technique is hereafter proposed to deal with the non-linear dynamics of the NPC converter while controlling the microgrid DC voltage.

A flexible control system for distributed generation with hybrid adaptive voltage and current control is presented in [7]. The control of active power is done using proportionalintegral (PI) compensation, even when there is frequency variation. However, despite the enhanced power quality system, it uses an LCL filter and it is only single-phase. We propose the use of NPC converters and robust BP control to improve the power quality, obtaining very low total harmonic distortion (THD) using only an L filter. The controller is designed for three-phase systems usually found in AC connected microgrids.

Lyapunov based backstepping control allows the design of robust and stable controllers. Virtual or intermediate reference quantities are used as intermediate control variables. Backstepping controllers can establish a relationship between the models of converters and control functions, ensuring the control system stability and robustness [38-44].

The backstepping control is used in [39,42] for a distributed hybrid photovoltaic panel that uses the DC-DC buck-boost converter linked to a single-phase inverter. In [39] the results show that this control method regulates the DC link of the DC-DC converter to obtain the maximum power point of the photovoltaic panel, and the AC current of the inverter contains low harmonic distortion. However, the control of the AC current of the single-phase inverter is done assuming separation of the DC link voltage dynamics to avoid distortion in the AC current due the DC load disturbances. Additionally, in the DC-DC buck-boost converter the control law is obtained by integration of the derivative of the duty cycle modulation function. The approach applied to 3-phase NPC converter results in very high gains and consequently the control laws are sensitive to $\mathrm{AC}$ voltage distortion. Therefore, to avoid sensitivity to AC voltage distortion while easing the control law, a novel backstepping approach is hereafter presented, which in addition reduces digital signal processing time. It allows the NPC converter, interconnecting a hybrid microgrid, to control the DC voltage and AC currents with high power quality, without assuming dynamic separation.

Predictive control applied to power converters is a simplification of optimal control theory valid given the converter discrete nature and finite number of switching states. 
Predictive controllers for power converters follow the subsequent design steps [37]: (a) the power converter dynamic model is obtained, identifying the switching states and their relationship to voltages or currents; (b) a cost function is defined to represent the desired behavior of the system; (c) the dynamic model is discretized to predict which is the best switching state to optimize the cost function. This approach needs to predict output currents resulting from the application of all the NPC 27 vectors.

The new backstepping predictive control method here proposed, applied to the NPC converters in hybrid microgrids, innovates in the predictive control design in steps (a) where the model is used to compute the NPC control vectors, using a Lyapunov candidate function to ensure stability; (b) the cost functional is defined with the weighted errors of the control vectors regarding the applied vectors; (c) the NPC optimal switching state is obtained by minimizing the norm of the distance between the needed control vector and the NPC converter available vectors. This new approach was not reported previously in the backstepping or in predictive literature [37,42] and avoids predicting the converter outputs for all the 27 vectors.

When the DC microgrid is in the voltage control mode, the backstepping method is applied to the error of the squares of DC voltage and its reference value to obtain the virtual $\mathrm{AC}$ current. When the $\mathrm{AC}$ microgrid is in the power control mode, the power of the AC microgrid is set and the DC microgrid operates as the source microgrid.

The obtained control laws define the NPC output vector required to control the NPC AC currents and to balance its capacitor voltages. Since the available NPC vectors are only 27 , the minimization of a cost function (like in the predictive approach) is used to find the NPC available vector closer to the required. This technique is termed backstepping predictive (BP).

Simulation and experimental results show that the BP controlled NPC converter is capable of regulating the DC microgrid voltage at the interconnection point by adjusting the power conversion of the AC microgrid to compensate for the variations of the DC microgrid voltage, which depend on the variations of the DC loads and distributed power sources. The NPC capacitors voltage balancing with the BP method is much faster than the PWM backstepping method with carrier offset. AC currents show lower harmonic distortion and the power factor is almost unitary. In the AC microgrid power control mode, the fast power step response shows that the converter is useful to regulate the microgrid $\mathrm{AC}$ frequency, primary power control, or to adjust the power level in secondary power control. These capabilities can be advantageously used to further strengthen smart grid operation.

The BP control method of the hybrid microgrid applied to the NPC converter is stable, robust, and with fast response in AC power conversion to deal with variations of the DC microgrid voltage, to balance the capacitor voltages or to adjust the power/frequency level of the AC microgrid.

\section{Hybrid Microgrid Models and Controller Design}

This section designs the modified backstepping method for the NPC converter interconnecting a hybrid microgrid. Control is applied to DC microgrid voltage or to AC microgrid power/frequency. The power factor is controlled to be near unity.

Figure 4 shows the circuit of the NPC converter that interconnects the DC microgrid section to the AC microgrid. The voltage $U_{d c}$ is the DC microgrid voltage, $i_{d c}$ is the current flowing from the DC microgrid, through the NPC, and currents $i_{1}, i_{2}$, and $i_{3}$ are the three phase AC currents of the AC microgrid, which flow into the three AC phases with voltages $U_{L 1}, U_{L 2}$, and $U_{L 3}$, using coupling coils, with self-induction coefficient, $L$, and loss resistance, $R$. The NPC converter two capacitors, $C_{1}$ and $C_{2}$, have voltages $U_{C 1}$ and $U_{C 2}$, 
which should be approximately balanced to $U_{d c} / 2$. The legs of the NPC converter can have three states, characterized by the variable $\gamma_{k}$ :

$$
\gamma_{k}= \begin{cases}1 & S_{k 1}=1 \text { and } S_{k 2}=1 \\ 0 & S_{k 1}=0 \text { and } S_{k 2}=1 \\ -1 & S_{k 1}=0 \text { and } S_{k 2}=0\end{cases}
$$

where $k, \in\{1,2,3\}$, and $S_{k 3}=1-S_{k 1}$ and $S_{k 4}=1-S_{k 2}$.

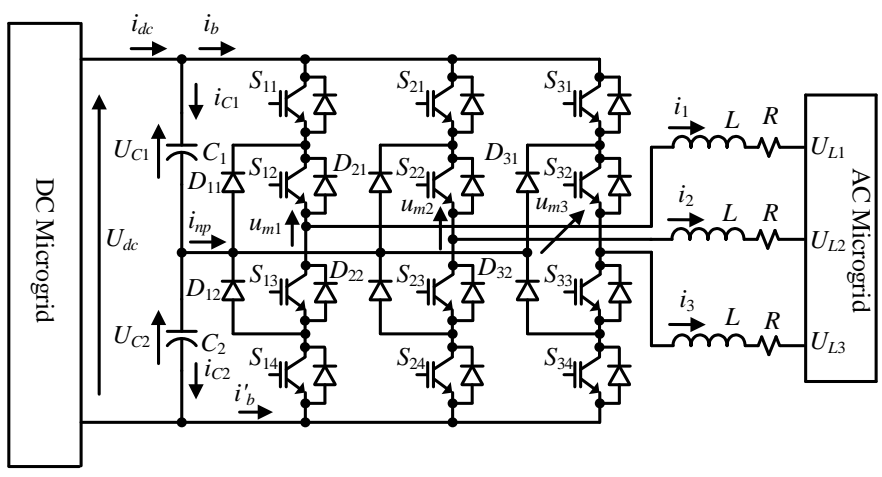

Figure 4. NPC converter circuitry interconnecting a hybrid microgrid.

\subsection{Model of NPC Converter in Hybrid Microgrids}

The time $t$ dynamic equations of currents $i_{d}$ and $i_{q}$, in $d q$, are obtained by applying Kirchhoff laws to Figure 4, and the Clark-Concordia and Park transforms to AC currents and voltages [27]:

$$
\begin{aligned}
& \frac{d i_{d}}{d t}=-\frac{R}{L} i_{d}+\omega i_{q}+\frac{\gamma_{d}}{L} \frac{U_{d c}}{2}-\frac{U_{L d}}{L} ; \\
& \frac{d i_{q}}{d t}=-\omega i_{d}-\frac{R}{L} i_{q}+\frac{\gamma_{q}}{L} \frac{U_{d c}}{2}-\frac{U_{L q}}{L} .
\end{aligned}
$$

The $i_{d}$ and $i_{q}$ currents are the AC NPC currents, $i_{1}, i_{2}$, and $i_{3}$, in their direct and quadrature components, respectively, $\omega$ is the angular frequency of the AC microgrid, $\gamma_{d}$, $\gamma_{q}$, and $\gamma_{0}$ represent the semiconductors on-off state, $\gamma_{1}, \gamma_{2}$, and $\gamma_{3}$ in $d q$ coordinates and $U_{L d}$ and $U_{L q}$ are the direct and quadrature voltages of the AC microgrid. It is observed that the dynamics of currents $i_{d}$ and $i_{q}$ are non-linear, but can be controlled by $\gamma_{d}$ and $\gamma_{q}$, respectively.

The equation that describes the dynamic evolution of DC voltage, in $d q$ coordinates, is given by [27]:

$$
\frac{d U_{d c}}{d t}=-\frac{\gamma_{d}}{C} i_{d}-\frac{\gamma_{q}}{C} i_{q}+\frac{2}{C} i_{d c} .
$$

This equation indicates that the dynamics of the DC voltage can be enforced using the current $i_{d}$, while the quadrature current $i_{q}$ and DC current $i_{d c}$ can be considered as disturbances. In the DC voltage dynamics equation, it is supposed $C_{1}=C_{2}=C$. In the NPC converter, the $i_{d}$ current is considered the virtual control input (AC current) to control the $\mathrm{DC}$ voltage, when control is applied to the voltage at the interconnection point of the DC microgrid.

In the DC terminals of the NPC converter, the dynamic behavior of the capacitor voltage unbalance error, $e_{U C}=U_{C 1}-U_{C 2}$, is given by [27]:

$$
\frac{d e_{U C}}{d t}=\frac{\gamma_{d}^{2}}{C} i_{d}+\frac{\gamma_{q}^{2}}{C} i_{q}
$$




\subsection{Design of DC Backstepping Virtual Control Input}

To control the DC microgrid voltage, using the backstepping method, the error between the squares of the DC voltage reference and the DC voltage, $e_{U d c}{ }^{2}$, is defined as

$$
e_{U d c^{2}}=U_{d c R e f}^{2}-U_{d c^{\prime}}^{2}
$$

where $U_{d c R e f}$ is the reference DC voltage of the DC microgrid. Let the Lyapunov function, $V_{1}$, positive definite, be [44]:

$$
V_{1}=\frac{e_{u d c^{2}}^{2}}{2}
$$

To ensure stability, the $V_{1}$ time derivative must be negative definite [44]:

$$
\frac{d V_{1}}{d t}=e_{U d c^{2}} \frac{d e_{U d c^{2}}}{d t}=-K_{e U d c^{2}}^{2} e_{U d c^{2}}
$$

where $K_{e U d c}{ }^{2}$ is a positive constant. Substituting in (8) the error between the DC voltage squares, $e_{U d c}{ }^{2}(6)$, the squared DC voltage dynamics equation, (4), and after some manipulation, the reference value for the virtual control current, $i_{d R e f D C}$, is obtained:

$$
i_{d R e f D C}=\frac{C}{2 \gamma_{d}}\left(-\frac{K_{e U d c^{2}}}{U_{d c}} e_{U d c^{2}}-\frac{1}{U_{d c}} \frac{d U_{d c R e f}^{2}}{d t}-\frac{2}{C} \gamma_{q} i_{q}+\frac{4}{C} i_{d c}\right)
$$

Equation (9) can be simplified. Considering a unit power factor, the quadrature AC current component is nearly zero $\left(i_{q} \approx 0\right)$. The direct component of the switch state variable, $\gamma_{d}$, which corresponds to the duty factor $\left(\gamma_{d} \neq 0\right)$, is approximately equal to $\gamma_{d} \approx 2 U_{L d} / U_{d c}$, obtained from (2) at steady state and neglecting losses. Therefore, the reference current, $i_{\text {dRefDC }}$, is given under the above conditions by

$$
i_{d R e f D C}=\frac{C}{4 U_{L d}}\left(-K_{e U d c^{2}} e_{U d c^{2}}-\frac{d U_{d c R e f}^{2}}{d t}+\frac{4 U_{d c}}{C} i_{d c}\right) .
$$

In DC microgrids for the voltage control mode the reference virtual direct current is $i_{d R e f}=i_{d R e f D C}$. To control the $i_{d}$ current, the $i_{d}$ current error, $e_{i d}$, is defined by

$$
e_{i d}=i_{d R e f}-i_{d}
$$

where $i_{d R e f}$ is the reference current, or virtual current, obtained in (10). Using a composite positive definite Lyapunov function, $V_{2}$ :

$$
V_{2}=V_{1}+\frac{e_{i d}^{2}}{2}=\frac{e_{u d c^{2}}^{2}}{2}+\frac{e_{i d}^{2}}{2}
$$

which is the sum the quadratic errors of the voltage $U_{d c}$ squared and the current $i_{d}$. The $V_{2}$ time derivative must be negative to ensure stability:

$$
\frac{d V_{2}}{d t}=e_{U d c^{2}} \frac{d e_{U d c^{2}}}{d t}+e_{i d} \frac{d e_{i d}}{d t}=-K_{e U d c^{2}} e_{U d c^{2}}^{2}-K_{e i d} e_{i d^{\prime}}^{2}
$$

where $K_{e U d c}{ }^{2}$ was defined in (8) and $K_{\text {eid }}$ is a positive constant. Substituting in (13) $e_{U d c}{ }^{2}$ and $e_{i d}$ by (6) and (11), respectively, using the dynamic behavior equation of current $i_{d}$, (2), and squaring the $U_{d c}$ voltage, (4), after algebraic manipulation, the reference component, $\gamma_{d R e f}$, to control the converter $\gamma_{d}$ is obtained,

$$
\gamma_{d R e f}=\frac{2 L}{U_{d c}}\left(K_{e i d} e_{i d}-\frac{2 \gamma_{d}}{C} e_{U d c^{2}}+\frac{d i_{d R e f D C}}{d t}+\frac{R}{L} i_{d}-\omega i_{q}+\frac{U_{L d}}{L}\right) .
$$


Defining the error of the quadrature current component, $i_{q}$,

$$
e_{i q}=i_{q R e f}-i_{q},
$$

where $i_{q R e f}$ is the reference $i_{q}$ current, which should be zero if a unit power factor is required $\left(i_{q R e f}=0\right)$. Choose again a positive definite Lyapunov function, $V_{3}(16)$, and compute its time derivative (17):

$$
\begin{gathered}
V_{3}=\frac{e_{i q}^{2}}{2}, \\
\frac{d V_{3}}{d t}=e_{i q} \frac{d e_{i q}}{d t}=-K_{e i q} e_{i q}^{2} .
\end{gathered}
$$

Assuming $K_{\text {eiq }}>0$ guarantees the control stability criterion. Substituting in (17) the current error $i_{q}, e_{i q}$, and using (3), which defines the dynamic behavior of the current $i_{q}$, it is received the reference component, $\gamma_{q R e f}$, of the quadrature control of the converter legs state $\gamma_{q}$,

$$
\gamma_{q R e f}=\frac{2 L}{U_{d c}}\left(K_{e i q} e_{i q}+\frac{d i_{q R e f}}{d t}+\frac{R}{L} i_{q}+\omega i_{d}+\frac{U_{L q}}{L}\right) .
$$

To balance the error of capacitor voltages, the positive Lyapunov function $V_{4}$ is chosen and defined by:

$$
V_{4}=\frac{e_{U C}^{2}}{2}
$$

Computing the time derivative of $V_{4}, d V_{4} / d t$, and making it negative gives:

$$
\frac{d V_{4}}{d t}=e_{U C} \frac{d e_{U C}}{d t}=-K_{e U C} e_{U C}^{2}
$$

where $K_{e U C}$ is a positive constant. Substituting in (20) the equation of the dynamic model of the capacitor voltage unbalance error gives the control law with the reference current, $I_{\text {eUCRef }}$, to balance capacitor voltages,

$$
I_{e U C R e f}=-C K_{e U C} e_{U C} \text {. }
$$

The current for balancing capacitor voltages is given by the product of the squares of the switch legs control variables, $\gamma_{d}$ and $\gamma_{q}$, with the currents, $i_{d}$ and $i_{q}$, respectively,

$$
I_{e U C}=\gamma_{d}^{2} i_{d}+\gamma_{q}^{2} i_{q} .
$$

\subsection{Design of DC Backstepping Predictive (BP) Controller}

The NPC converter, Figure 4, according to (1), has 27 possible combinations of the converter switch legs states. A cost functional is defined with the weighted errors, for normalization, of the converter switch state legs variables, $e_{\gamma d}$ and $e_{\gamma q}$, and the current that allows the capacitor voltages to be balanced, $e_{\text {IeUC }}$, are given by:

$$
\begin{gathered}
e_{\gamma d}=\frac{\gamma_{d R e f}-\gamma_{d}}{\rho_{\gamma d}} ; \\
e_{\gamma q}=\frac{\gamma_{q R e f}-\gamma_{q}}{\rho_{\gamma q}} ; \\
e_{\text {IeUC }}=\frac{I_{e U C R e f}-I_{e U C}}{\rho_{\text {IeUC }}} .
\end{gathered}
$$


The error weights $\rho_{\gamma d}$ and $\rho_{\gamma q}$ of the converter switch leg states, and $\rho_{\text {IeUC }}$ for the current to balance the capacitor voltages, allow normalizing the errors while adjusting the control action of the quantities to be controlled. The cost functional $C F_{\text {Predictive }}$ is given by

$$
C F_{\text {Predictive }}=\sqrt{e_{\gamma d}^{2}+e_{\gamma q}^{2}+e_{\text {IeUC }}^{2}} \text {. }
$$

Predictive control algorithm applies all 27 combinations of converter switch leg states to calculate the cost functional, $C F_{\text {Predictive, }}$ and choose the combination that minimizes the cost functional for controlling DC microgrid voltage and AC currents and to balance the capacitor voltages, using the BP equations, ensuring control stability.

The drive of the NPC converter semiconductors can also be done using PWM modulation instead of the predictive control, with the cost functional, using the same backstepping control equations. With PWM modulation the capacitor voltage balance can be achieved by introducing and feedback regulating a carrier waveform offset. The PWM modulation further reduces the computational cost, suitable for low cost processors, but the results will show that the convergence speed of the capacitor voltage balance is slower than with the BP control.

\subsection{AC Microgrid BP Controller Design}

In $A C$ microgrid power/frequency control mode the active power reference, $P_{\text {RefAC }}$, is defined and from the AC microgrid power equation, $P_{A C}$,

$$
P_{A C}=U_{L d} i_{d}+U_{L q} i_{q}
$$

the reference current (28) of the AC microgrid, $i_{d R e f A C}$, is calculated, assuming a rotating reference frame where the quadrature voltage is null, $U_{L q}=0$.

$$
i_{d \operatorname{Ref} A C}=\frac{P_{\operatorname{Ref} A C}}{U_{L d}}
$$

The NPC converter interconnecting a hybrid microgrid can operate in DC voltage control mode, Mode = 1 (Section 2.2), or AC microgrid active power control mode, Mode= 0 , described in this Section 2.4. The direct current reference, $i_{d R e f}$, is defined as a function of the control mode by:

$$
i_{\text {Ref }}=i_{d R e f D C} \text { Mode }+i_{d R e f A C}(1-\text { Mode }) .
$$

The design of the AC microgrid BP controller is similar to those of the DC microgrid. However, in this control mode the DC voltage, $U_{d c}$, is the DC microgrid voltage. Defining a positive Lyapunov function, $V_{2 A C}$, in (30) to control the $i_{d}$ current, its time derivative is (31).

$$
\begin{gathered}
V_{2 A C}=\frac{e_{i d}^{2}}{2} \\
\frac{d V_{2 A C}}{d t}=e_{i d} \frac{d e_{i d}}{d t}=-K_{e i d} e_{i d}^{2}
\end{gathered}
$$

Assuming $K_{\text {eid }}>0$ ensures the control stability criterion. Substituting in (31) the error of $i_{d}$ current, $e_{i d}$, and using (2), which defines the dynamic behavior of current $i_{d}$, gives the reference component, $\gamma_{d P R e f}$, of the direct control quantity,

$$
\gamma_{d P R e f}=\frac{2 L}{U_{d c}}\left(K_{e i d} e_{i d}+\frac{d i_{d R e f}}{d t}+\frac{R}{L} i_{d}-\omega i_{q}+\frac{U_{L d}}{L}\right) .
$$

The difference in AC microgrid control mode from DC microgrid control mode is in the direct current reference setting, $i_{d R e f}$. In the DC microgrid the control law is (14) to control the DC voltage, $U_{d c}$. In the AC microgrid the value is calculated as a function of the 
active power, which allows one to adjust the power/frequency of the AC microgrid. In the AC microgrid the control law of the direct variable to control the converter legs (32) does not have the error between the DC voltage squares, $e_{U d c}{ }^{2}$ as in (14).

The same cost functional (26) is used to control the hybrid microgrid NPC converter in the AC power mode (Mode $=0)$.

\subsection{Block Diagram of DC/AC BP Controller}

The design of the $\mathrm{DC}$ microgrid $\mathrm{BP}$ controller must ensure regulation of the $\mathrm{DC}$ voltage, control the AC input currents so that the power factor is almost unity and the voltages of the capacitors are balanced. The AC microgrid BP controller regulates $\mathrm{AC}$ power, supporting the frequency control and voltage of the $\mathrm{AC}$ microgrid. The hybrid microgrid $\mathrm{AC} / \mathrm{DC}$ $\mathrm{BP}$ control was designed using the explained BP methodology. Figure 5 shows the block diagram with the BP controller for NPCs interconnecting hybrid microgrids.

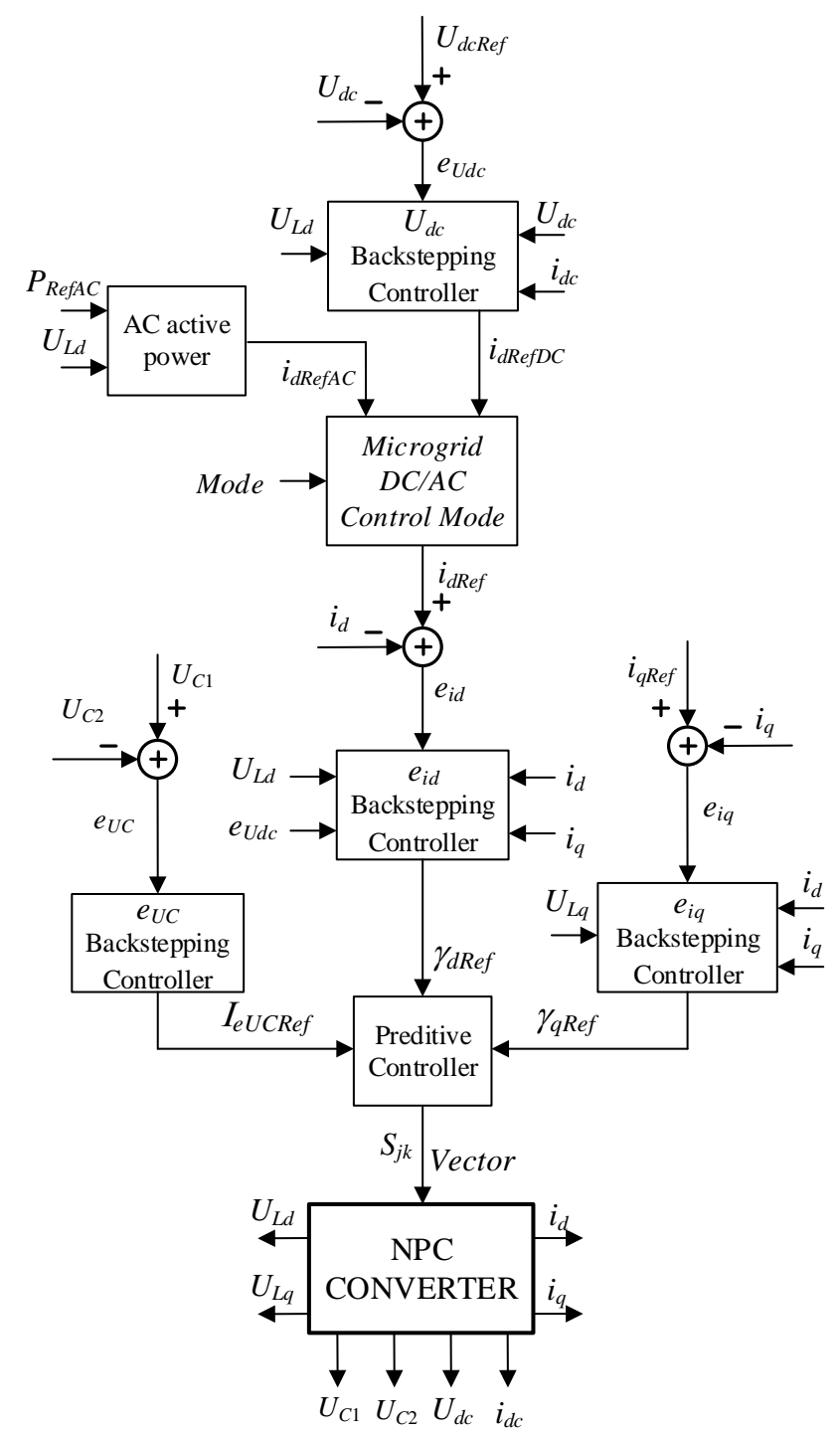

Figure 5. Hybrid microgrid AC/DC BP control diagram.

In the control block diagram for the hybrid microgrid the converter voltage of the DC microgrid is sampled and compared to the reference. Applying the backstepping method to the voltage dynamics Equation (4) results in the voltage controller, which calculates the virtual current value, $i_{\text {drefDC }}$. 
From the reference AC power, $P_{\text {RefAC }}$, the virtual current value, $i_{\text {dref } A C}$, is calculated. In the DC microgrid control mode (Mode $=1$ ), which regulates the DC voltage, $i_{\text {dref }}=i_{\text {dref } D C}$. In the power/frequency control mode of the AC microgrid $(M o d e=0)$ it is $i_{\text {dref }}=i_{\text {drefAC }}$. AC currents are sampled and the Park transform applied. The obtained $d q$ currents, $i_{d}$ and $i_{q}$, are compared to the virtual quantities, $i_{d R e f}$ and $i_{q R e f}=0$. The application of the BP control method results in defining the legs control variables, $\gamma_{d R e f}$ and $\gamma_{q R e f}$. The BP method is also applied to the capacitor voltage error to obtain the $I_{e U C R e f}$ current needed to balance the capacitors voltage. The predictive controller analyses all combinations of semiconductor states to minimize the cost of a functional based on the weighted errors of the available control actions.

\section{Simulation and Experimental Results of the Hybrid Microgrid}

This section presents the simulation and experimental results of the hybrid microgrid. The simulations in MATLAB/Simulink were based on the hybrid microgrid model and on the controller obtained by the BP method. Experimental results were obtained from a laboratory prototype of the NPC converter, Figure 4, which was implemented to experimentally test the performance of the hybrid microgrid.

Simulation and experimental results are presented in the steady state, for the DC and AC microgrid, and in transient operation. Simulation and experimental results of the BP controller are compared.

Table 1 lists the parameters and values used in the simulation and experimental verification.

Table 1. Hybrid microgrid parameters and values.

\begin{tabular}{cc}
\hline Parameter & Value \\
\hline DC microgrid voltage $\left(U_{d c}\right)$ & $200 \mathrm{~V}$ \\
Capacitance NPC converter $(C)$ & $4.4 \mathrm{mF}$ \\
Self-induction coefficient $(L)$ & $15.1 \mathrm{mH}$ \\
Loss resistance $(R)$ & $0.1 \Omega$ \\
Grid rated voltage $\left(U_{L}\right)$ & $60 \mathrm{~V}$ \\
Angular frequency $(\omega)$ & $2 \pi f$ \\
Constant $K_{e U d c}$ & $3 U_{d c}$ \\
Constant $K_{e i d}$ & $20 / t_{s}$ \\
Constant $K_{e i q}$ & $20 / t_{s}$ \\
Constant $K_{e U C}$ & $1 / t_{s}$ \\
Error weight $\rho_{\gamma d}$ & 1 \\
Error weight $\rho_{\gamma q}$ & 1 \\
Error weight $\rho_{\text {IeUC }}$ & 0.1 \\
Frequency $(f)$ & $50 \mathrm{~Hz}$ \\
Sampling time $\left(t_{s}\right)$ & $28 \mu \mathrm{s}$ \\
\hline
\end{tabular}

\subsection{Microgrid Results}

This section shows the results of the operation of the hybrid microgrid with the converter controlling the voltage of the DC microgrid. Figure 6 shows the simulation results of the DC voltage and AC currents of the microgrid using the BP control method.

Simulation results show that in the steady state the BP DC voltage controller regulates the DC microgrid voltage. AC currents are sinusoidal, with low harmonic distortion, $1.7 \%$. In the laboratory prototype the results of the DC voltage control and the AC currents control present the same behavior as the simulation results of Figure 6. 


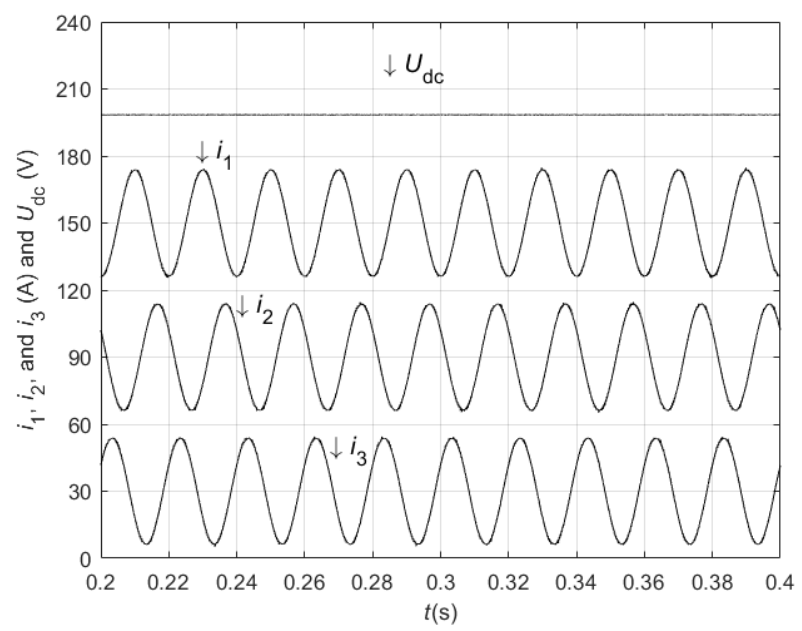

Figure 6. Simulation results of DC voltage and AC currents. AC currents, $i_{1}, i_{2}$, and $i_{3}$, are amplified by a factor of 3 and displaced by 150,90, and 30, respectively.

Simulation results of capacitor voltages are shown in Figure 7. These results show that from a $10 \%$ voltage imbalance the BP controller takes approximately $0.05 \mathrm{~s}$ to balance the capacitor voltage (Figure 7a). Compared to PWM modulation, whose capacitor voltage balance is obtained by adjusting the carrier offset in a process that takes approximately $1.6 \mathrm{~s}$ (Figure $7 \mathrm{~b}$ ), it is concluded this time is too long to enable the use of NPC converters with PWM modulation and carrier offset control in a bipolar microgrid.

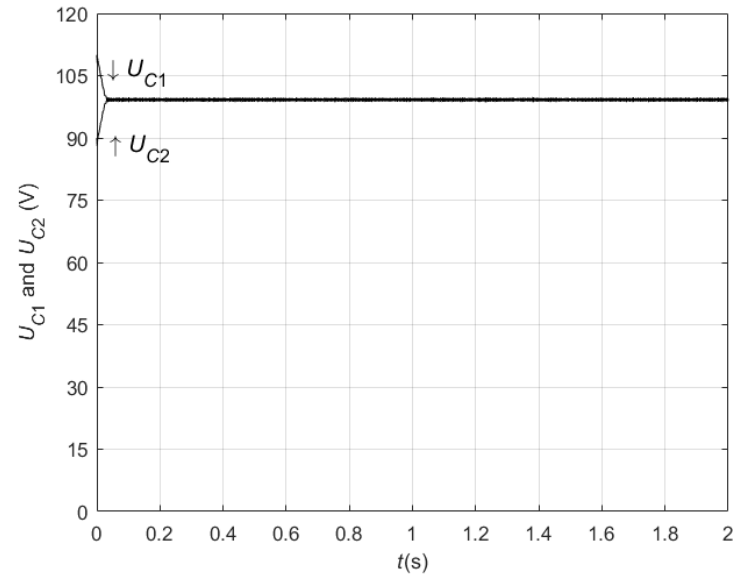

(a)

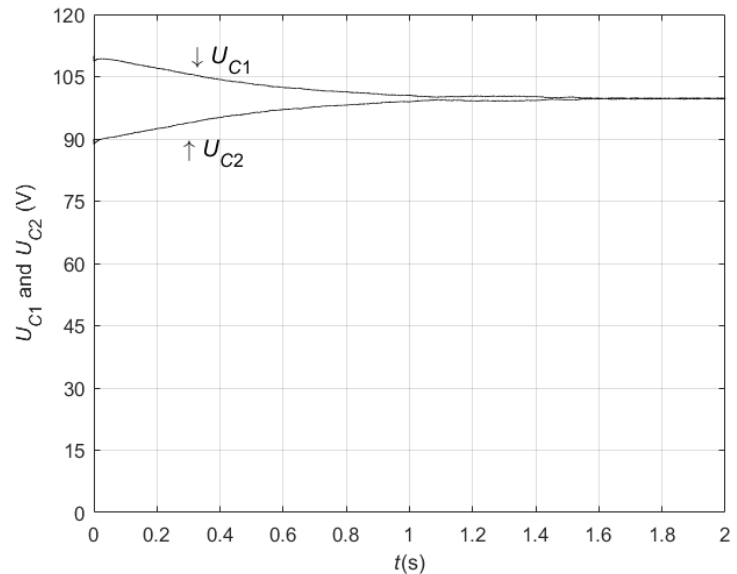

(b)

Figure 7. Simulation results comparison in steady state, of the capacitor voltage $U_{C 1}$ and $U_{C 2}$ using: (a) backstepping predictive and (b) backstepping with PWM.

The experimental and simulation results of Figure 8 show the response of the predictive control NPC converter contributing to the regulation of the DC voltage at the interconnection point when there is a power step variation on the load or on the distributed renewable energy sources in the DC microgrid. Figure $8 \mathrm{a}, \mathrm{c}$ shows the case where there is a $100 \%$ increase in the load power. The BP controller adjusts the reference current of the AC microgrid, $i_{d R e f D C}(10)$, to compensate for the voltage droop $U_{d c}$. In Figure $8 \mathrm{~b}, \mathrm{~d}$ there is a $50 \%$ reduction on the load power, causing a reduction of the DC microgrid voltage droop. The results of Figure 8 show that the static error of the $U_{d c}$ voltage is lower than $0.5 \%$. In Figure 8a,c, during the transient, there is a reduction in DC voltage of approximately $1 \%$. In Figure $8 \mathrm{~b}, \mathrm{~d}$ there is an increase of about $1 \%$, during the transient. After the transient, the DC voltage follows the reference with the above stated static error. The result also 
shows that the AC microgrid currents are almost sinusoidal $(1.8 \%$ and $1.7 \%$ total harmonic distortion for experimental and simulation results, respectively) and with a fast response to load changes in the DC microgrid. The current step response time is in the order of the $\mathrm{ms}$, limited by filtering inductors and available voltages and not by the controller.

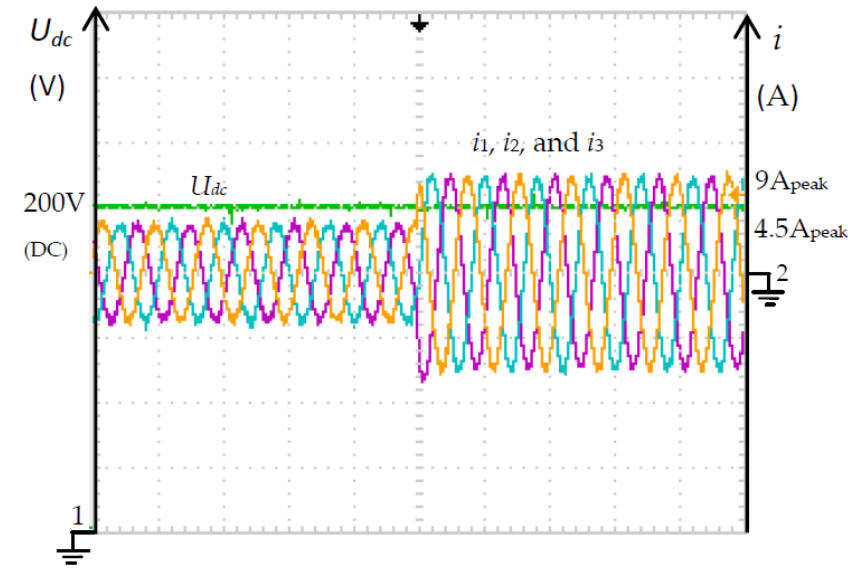

(a) Experimental results.

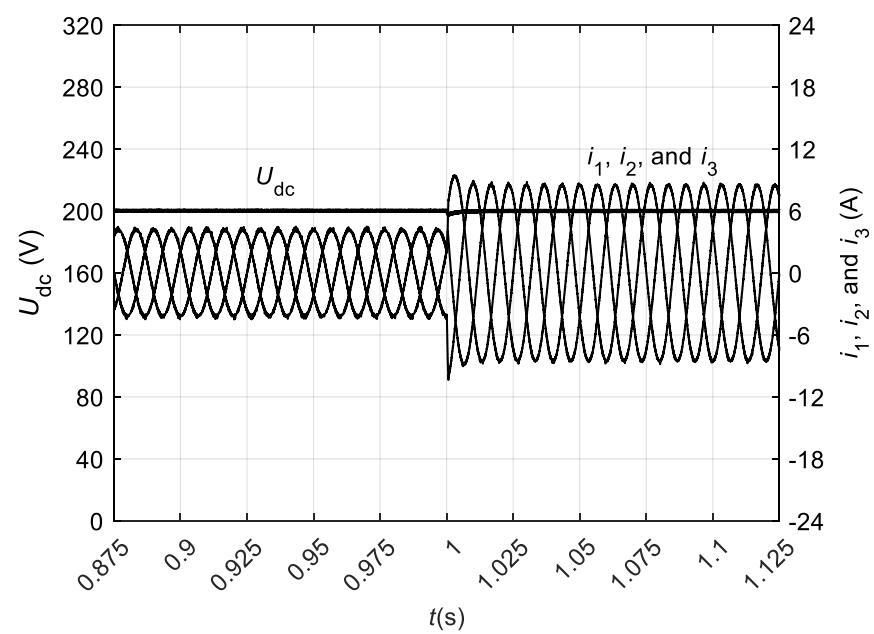

(c) Simulation results.

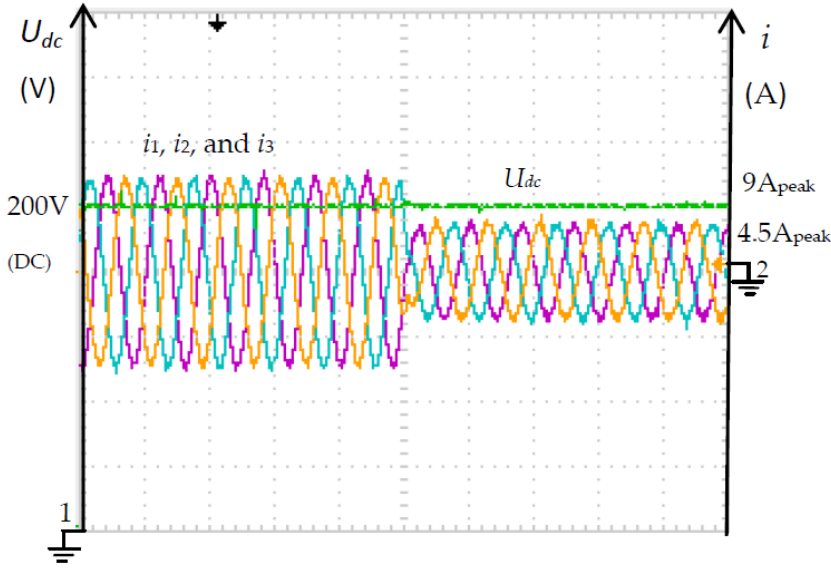

(b) Experimental results.

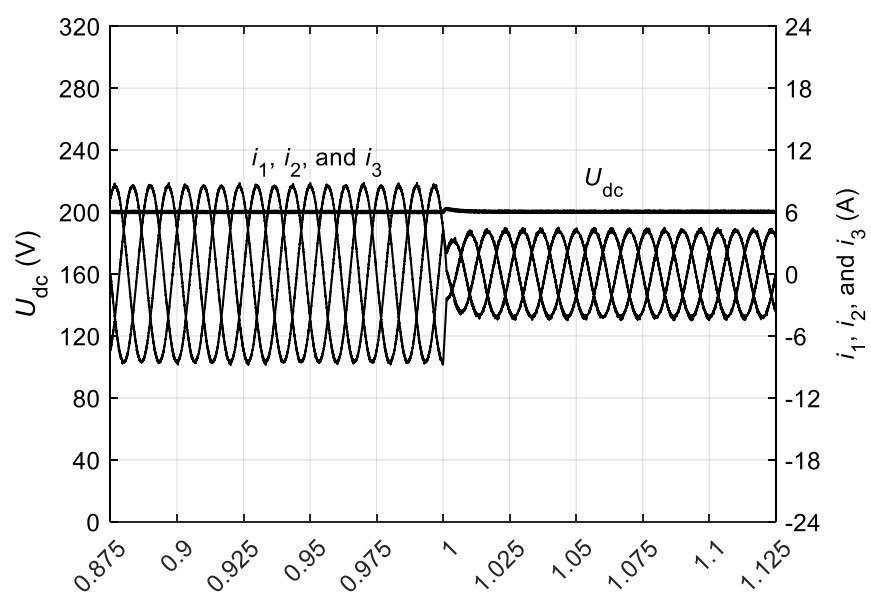

$t(\mathrm{~s})$

(d) Simulation results.

Figure 8. Experimental and simulation results of the DC voltage and AC currents, $i_{1}, i_{2}$, and $i_{3}$, of the DC microgrid when there is a step change in load or generation. $(\mathbf{a}, \mathbf{c})$ Increased load or decreased generation. $(\mathbf{b}, \mathbf{d})$ Decreased load or increased generation. Vertical: $6 \mathrm{~A} /$ div and $40 \mathrm{~V} /$ div. Horizontal: $25 \mathrm{~ms} /$ div.

Both the simulation and experimental results show that the BP controller applied to the hybrid microgrid NPC converter in the DC microgrid voltage control mode, Mode = 1, control the DC voltage, balance the capacitors voltages and AC currents, in the steady state and transient operation.

\subsection{AC Microgrid Results}

This section shows the results of the operation of the hybrid microgrid in the AC power/frequency control mode, Mode $=0$. In this mode of operation, the grid operator (secondary control) can set the active power, or reference AC current, to help adjusting the power or the frequency of the AC microgrid. Figure 9 shows the experimental results for a stepwise increase of the AC power injected into the AC grid to twice the previous value. The AC currents were almost sinusoidal (THD $=1.8 \%$ ), balanced, with step response 
almost instantaneous, regarding the AC period, allowing the NPC converter to be used as a primary $\mathrm{AC}$ microgrid contributor for frequency regulation.

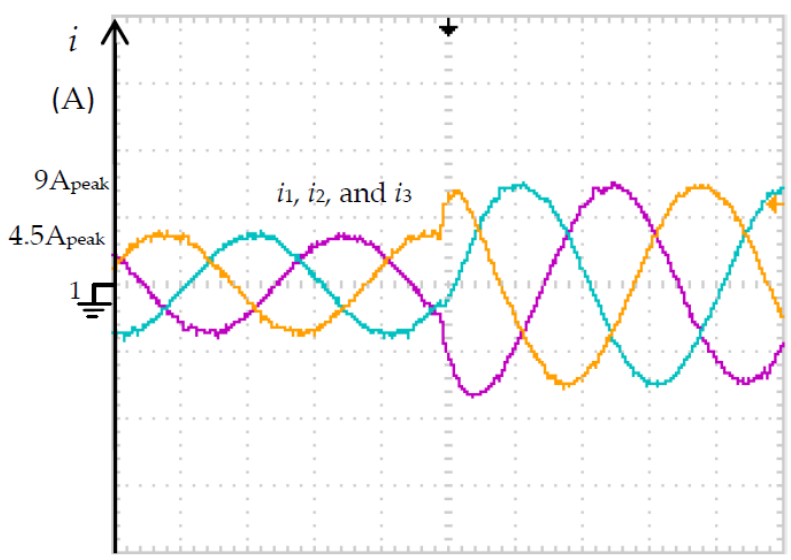

Figure 9. Experimental results of $\mathrm{AC}$ currents, $i_{1}, i_{2}$, and $i_{3}$, of $\mathrm{AC}$ microgrid when there is a variation of AC power in step. Vertical: $6 \mathrm{~A} /$ div. Horizontal: $5 \mathrm{~ms} /$ div.

Figure 10 shows the experimental results of $\mathrm{AC}$ current and voltage, $i_{1}$ and $U_{L 1}$, in this case to a stepwise increase of the reference AC power injected into the DC grid. The $\mathrm{AC}$ current increased from $4.5 \mathrm{~A}_{\text {peak }}$ to $9 \mathrm{~A}_{\text {peak }}$.

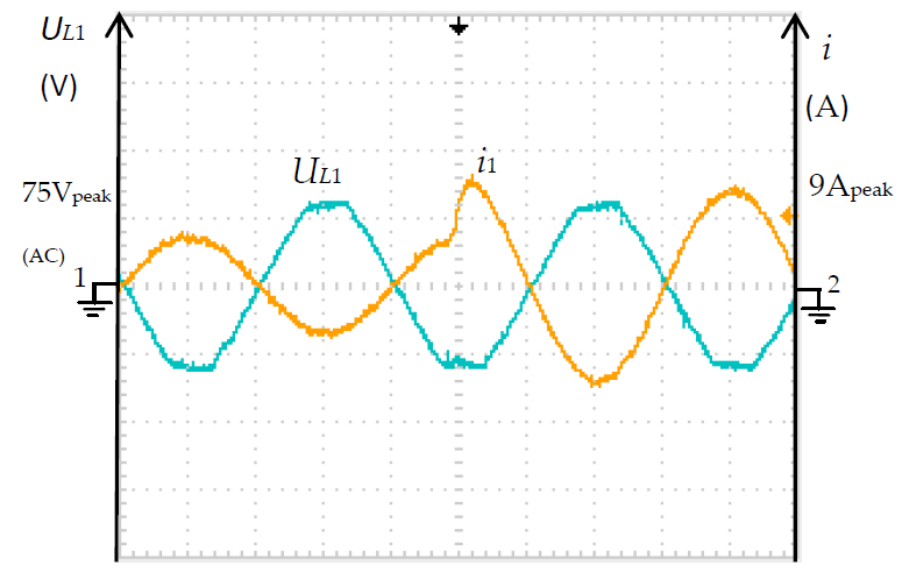

Figure 10. Experimental results of AC voltage and current, $U_{L 1}$ and $i_{1}$, of the $\mathrm{AC}$ microgrid when there is variation of the AC power in the step. Vertical: $6 \mathrm{~A} / \mathrm{div}$ and $60 \mathrm{~V} /$ div. Horizontal: $5 \mathrm{~ms} / \mathrm{div}$.

Experimental results (Figure 11a) of microgrid NPC converter in voltage mode control at the steady-state show low distortion almost sinusoidal AC currents with THD of $1.8 \%$ (Figure 11b).

Figure 12 shows an experimental transient of the DC voltage regulation using an integral proportional controller (PI), tuned using a damping factor of 0.7, and PWM modulation when there is a $100 \%$ increase in the DC load power. The results show that the PI adjusts the AC current, with a slower response time than the BP controller, causing a reduction of the DC voltage, during the transient, of approximately $3 \%$, and an increase in the steady state error. Besides, the AC currents show some unbalance, which causes higher DC voltage ripple. 


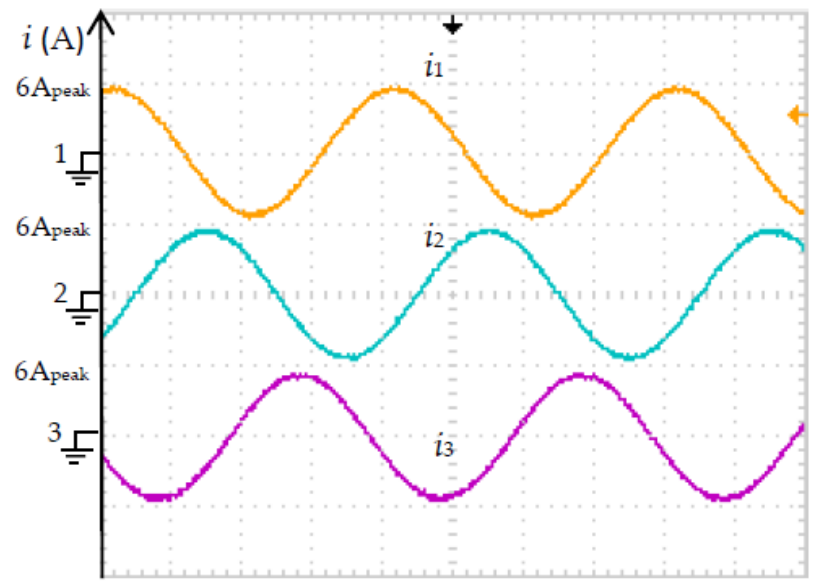

(a)

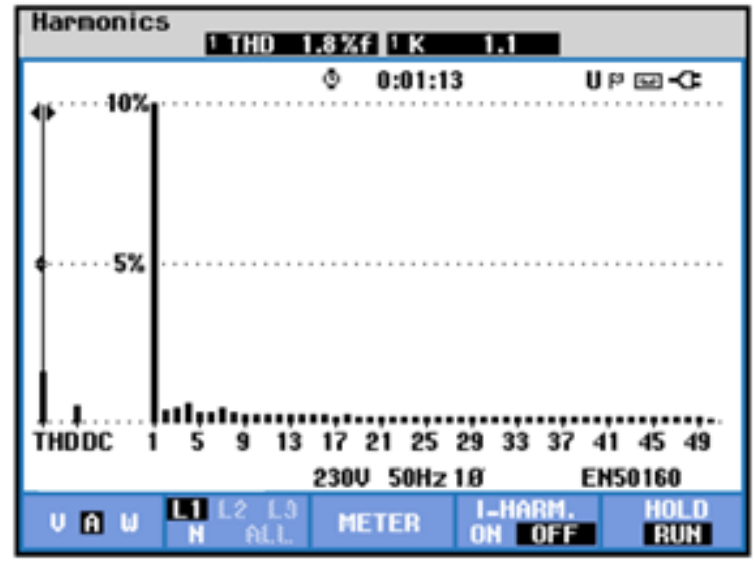

(b)

Figure 11. (a) Experimental results of AC currents, $i_{1}, i_{1}$, and $i_{3}$, Vertical: $6 \mathrm{~A} /$ div. Horizontal: 5 ms/div. (b) Experimental result of AC current, $i_{1}$, THD.

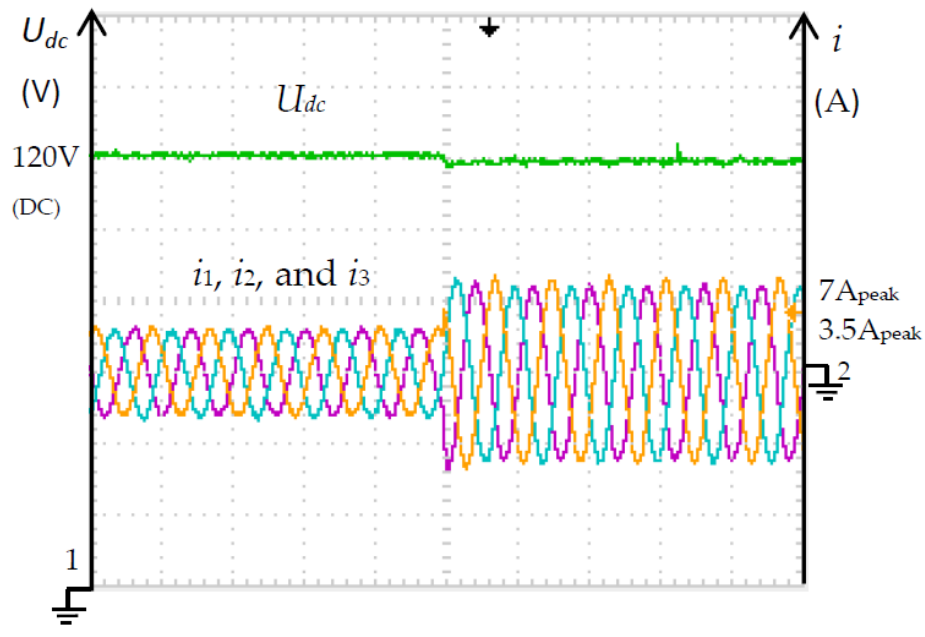

Figure 12. Experimental results of the DC voltage and AC currents, $i_{1}, i_{2}$, and $i_{3}$, of the DC microgrid when there is a step change in load or generation. Increased load using a DC voltage PI controller. Vertical: $6 \mathrm{~A} /$ div and $20 \mathrm{~V} /$ div. Horizontal: $5 \mathrm{~ms} /$ div.

Experimental results were obtained using the NPC prototype depicted in Figure 13, using digital scope $100 \mathrm{MS} / \mathrm{s}$ Tektronix TDS 2014, and class A power quality analyzer Fluke 435.

Simulation and experimental results show that the BP controller is capable of properly controlling the NPC converter to interconnect a hybrid microgrid. In the DC microgrid voltage control mode, proper conversion power adjustment between the AC microgrid and DC microgrid is observed to compensate for DC voltage variations caused by DC load changes or renewable generation at the converter point of interconnection. Using the $\mathrm{BP}$ controller allows to improve the capacitors voltage balance convergence time compared to PWM backstepping controller. The fast response of the AC current variation allows this converter to be used in the $\mathrm{AC}$ power control mode for both secondary $\mathrm{AC}$ power control and mainly primary AC frequency control. AC currents are sinusoidal, with low harmonic distortion, and the power factor is unitary.

The power factor can be made nearly unity, while the AC current (in periodic regime) is less distorted (THDi $\approx 1.8 \%$ ) than the $\mathrm{AC}$ voltage $U_{L 1}\left(\mathrm{THD}_{\mathrm{U}} \approx 2.5 \%\right.$ ). Regarding simulations and theoretical results, experimental deviations for the THDs are around $5 \%$, 
while deviations for the AC currents are around $8.8 \%$, as the theoretical model assumes a unity efficiency converter.

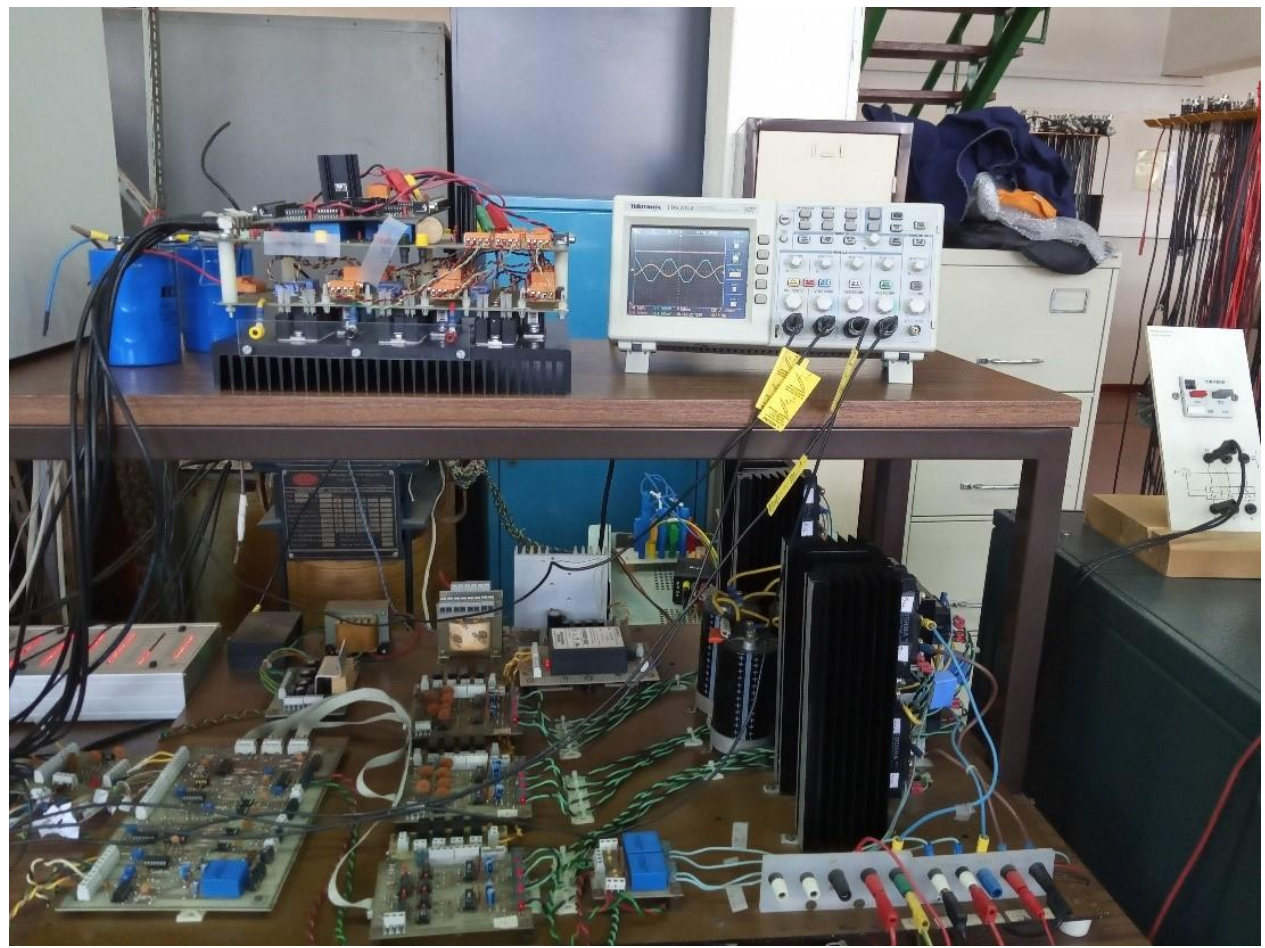

Figure 13. Picture of the lab prototype of the experimental system.

\section{Conclusions}

This paper presented a new control method, BP, for controlling hybrid microgrids interconnected with NPC converters. The converter, like three-phase two-level converters, can operate in the DC microgrids primary control mode using the AC microgrid as a source, or in the AC microgrid control mode as the DC microgrid as a source.

From the modelling of the NPC converter circuit that interconnects two hybrid microgrids, DC and $\mathrm{AC}$, the equations of the state space variables in $d q$ are presented. In the DC microgrid control mode, the BP controller was designed to control the DC grid voltage, balance the converter capacitors voltage, and control AC currents to have near unity power factor or control reactive power. In the AC microgrid control mode the relationship between $\mathrm{AC}$ power and $\mathrm{AC}$ currents are $\mathrm{BP}$ controlled to enforce the required active and reactive powers.

The MATLAB/Simulink simulation results and laboratory prototype experiments show that in the DC microgrid control mode the microgrid DC voltage at the converter interconnection point is regulated, the $\mathrm{AC}$ currents are almost sinusoidal (distortion around $1.7 \%$ ), the power factor is mostly unity and the $\mathrm{BP}$ controller presents fast response to the load or renewable power variations of the DC microgrid, converting more or less power from the $\mathrm{AC}$ microgrid, to compensate the $\mathrm{DC}$ load or renewable generation, contributing to the regulation of the DC microgrid voltage. The results show that the capacitor voltage balance is well matched and from a voltage imbalance it is found that the BP controller is much faster to balance the capacitor voltage compared to the carrier offset PWM method.

The tests carried out on the NPC converter, which interconnects two hybrid microgrids, can operate in the AC microgrid control mode. In this mode the AC microgrid operator sets the power level, which has fast step response, allowing the primary frequency or secondary power control to be assisted.

The BP approach can be further exploited in bipolar microgrids applications, where it can be used to balance the positive and negative voltages, in spite of positive/negative 
strong load mismatches or asymmetrical bipolar voltages. BP can also be used for a first preview of secondary control in microgrids.

Author Contributions: J.D.B., L.R. and J.F.S. designed and performed the experiments, analyzed the data, and wrote the manuscript. J.F.S. supervised the research, providing guidance theory, analyzed the data, and revised the paper. All authors have read and agreed to the published version of the manuscript.

Funding: This work was supported by national funds through FCT, Fundação para a Ciência e a Tecnologia, under project UIDB/50021/2020.

Data Availability Statement: This study presents the main data needed to reproduce the presented simulations and experiments. Non-essential data used in this study is available on request from the corresponding author. It is not publicly available as it is well known by experts in the field, and general variations on non-essential data do not change the results.

Conflicts of Interest: The authors declare no conflict of interest.

\section{List of Symbols}

\begin{tabular}{|c|c|}
\hline $\mathrm{AC}$ & Alternating current \\
\hline$C_{1}, C_{2}, C$ & Capacitance of capacitor \\
\hline$C F_{\text {Predictive }}$ & Cost functional \\
\hline $\mathrm{DC}$ & Direct current \\
\hline$e_{i d}$ & $i_{d}$ current error between $i_{d R e f}$ and the $i_{d}$ \\
\hline$e_{\text {IeUC }}$ & Current that allows the capacitor voltages to be balanced \\
\hline$e_{i q}$ & $i_{q}$ current error between $i_{q R e f}$ and the $i_{q}$ \\
\hline$e_{U d c}$ & Error between $U_{d c R e f}$ and the $U_{d c}$ \\
\hline$e_{U d c^{2}}$ & Error between the squares $U_{d c R e f}$ and the $U_{d c}$ \\
\hline$e_{\gamma d}, e_{\gamma q}$ & Switch state legs variables used in cost functional \\
\hline f & Frequency \\
\hline$i_{1}, i_{2}, i_{3}$ & Three phase AC currents of the AC microgrid \\
\hline$i_{d}, i_{q}$ & Direct and quadrature currents of the AC microgrid \\
\hline$i_{d c}$ & Current flowing from the DC microgrid \\
\hline$i_{d R e f}$ & Reference virtual control current \\
\hline$i_{d \operatorname{Ref} A C}$ & Reference current of the AC microgrid \\
\hline$i_{d R e f D C}$ & Virtual control current \\
\hline$I_{e U C}$ & Current to balance capacitor voltages \\
\hline$I_{e U C R e f}$ & Reference current to balance capacitor voltages \\
\hline$i_{q R e f}$ & Reference $i_{q}$ current \\
\hline$K_{\text {eid }}$ & Positive constant, used in stability condition of Lyapunov $V_{2}$ \\
\hline Keiq & Positive constant, used in stability condition of Lyapunov $V_{3}$ \\
\hline$K_{e U C}$ & Positive constant, used in stability condition of Lyapunov $V_{4}$ \\
\hline$K_{e U d c^{2}}$ & Positive constant, used in stability condition of Lyapunov $V_{1}$ \\
\hline$P_{\text {RefAC }}$ & Active power reference \\
\hline$P_{A C}$ & AC microgrid power \\
\hline$t$ & Time \\
\hline$U_{C 1}, U_{C 2}$ & Capacitor voltages of $C_{1}$ and $C_{2}$ \\
\hline$U_{d c}$ & DC microgrid voltage \\
\hline$U_{d c R e f}$ & DC microgrid voltage reference \\
\hline$U_{L d}, U_{L q}$ & Direct and quadrature voltages of the AC microgrid \\
\hline$U_{L 1}, U_{L 2}, U_{L 3}$ & Three phase AC voltages of the AC microgrid \\
\hline$V_{i}$ & Lyapunov function $\mathrm{n}^{\circ} i$, positive definitive \\
\hline$\gamma_{d}, \gamma_{q}$ & Switching variables $\gamma_{1}, \gamma_{2}, \gamma_{3}$ in $d q$ coordinates \\
\hline$\gamma_{d R e f}$ & Reference component to control the converter \\
\hline$\gamma_{k}$ & Switching variable with three states \\
\hline$\gamma_{q R e f}$ & Reference component of the quadrature control of the converter \\
\hline$\rho_{\gamma d}, \rho_{\gamma q}, \rho_{\text {IeUC }}$ & Error weights used in cost functional \\
\hline$\omega$ & Angular frequency \\
\hline
\end{tabular}




\section{References}

1. Lu, X.; Guerrero, J.M.; Sun, K.; Vasquez, J.C. An Improved Droop Control Method for DC Microgrids Based on Low Bandwidth Communication with DC Bus Voltage Restoration and Enhanced Current Sharing Accuracy. IEEE Trans. Power Electron. 2014, 29, 1800-1812. [CrossRef]

2. Lasseter, R.; Akhil, A.; Marnay, C.; Stephens, J.; Dagle, J.; Guttromson, R.; Meliopoulous, A.S.; Yinger, R.; Eto, J. The CERTS MicroGrid Concept, White Paper on Integration of Distributed Energy Resources; Technical Report; 2002. Available online: http: // bnrg.eecs.berkeley.edu/ randy/Courses/CS294.F09/MicroGrid.pdf (accessed on 27 January 2021).

3. Guerrero, J.M.; Vasquez, J.C.; Matas, J.; Vicuna, L.G.; Castilla, M. Hierarchical Control of Droop-Controlled AC and DC Microgrids-A General Approach toward Standardization. IEEE Trans. Ind. Electron. 2011, 58, 158-172. [CrossRef]

4. Nejabatkhahand, F.; Li, Y.W. Overview of Power Management Strategies of Hybrid AC/DC Microgrid. IEEE Trans. Power Electron. 2015, 30, 7072-7089. [CrossRef]

5. Rocabert, J.; Luna, A.; Blaabjerg, F.; Rodríguez, P. Control of Power Converters in AC Microgrids. IEEE Trans. Power Electron. 2012, 27, 4734-4749. [CrossRef]

6. Jamil, M.; Hussain, B.; Abu-Sara, M.; Boltryk, R.J.; Sharkh, S.M. Microgrid power electronic converters: State of the art and future challenges. In Proceedings of the 44th International Universities Power Engineering Conference (UPEC), Glasgow, UK, 1-4 September 2009; pp. 1-5.

7. He, J.; Li, Y.W.; Blaabjerg, F. Flexible Microgrid Power Quality Enhancement Using Adaptive Hybrid Voltage and Current Controller. IEEE Trans. Ind. Electron. 2014, 61, 2784-2794. [CrossRef]

8. Kaviri, S.M.; Pahlevani, M.; Jain, P.; Bakhshai, A. A review of AC microgrid control methods. In Proceedings of the IEEE 8th International Symposium on Power Electronics for Distributed Generation Systems (PEDG), Florianopolis, Brazil, 17-20 April 2017; pp. 1-8.

9. Li, K.; Hu, Y.; Ioinovici, A. Generation of the Large DC Gain Step-Up Non isolated Converters in Conjunction With Renewable Energy Sources Starting From a Proposed Geometric Structure. IEEE Trans. Power Electron. 2017, 32, 5323-5340. [CrossRef]

10. Shan, Y.; Hu, J.; Cheng, K.W.; Liu, M. A Universal Model Predictive Control for Practical AC Microgrids with PVs and Battery Energy Storage Systems. In Proceedings of the 2018 IEEE Energy Conversion Congress and Exposition (ECCE), Portland, OR, USA, 23-27 September 2018; pp. 6257-6262.

11. Wang, F.; Duarte, J.L.; Hendrix, M.A.M. Grid-Interfacing Converter Systems with Enhanced Voltage Quality for Microgrid Application-Concept and Implementation. IEEE Trans. Power Electron. 2011, 26, 3501-3513. [CrossRef]

12. Jadhav, A.M.; Patne, N.R.; Guerrero, J.M. A Novel Approach to Neighborhood Fair Energy Trading in a Distribution Network of Multiple Microgrid Clusters. IEEE Trans. Ind. Electron. 2019, 66, 1520-1531. [CrossRef]

13. Parhizi, S.; Lotfi, H.; Khodaei, A.; Bahramirad, S. State of the Art in Research on Microgrids: A Review. IEEE Access 2015, 3 , 890-925. [CrossRef]

14. Hofer, J.; Svetozarevic, B.; Schlueter, A. Hybrid AC/DC building microgrid for solar PV and battery storage integration. In Proceedings of the IEEE Second International Conference on DC Microgrids (ICDCM), Nuremburg, Germany, 27-29 June 2017; pp. 188-191.

15. Kanchev, H.; Lu, D.; Colas, F.; Lazarov, V.; Francois, B. Energy Management and Operational Planning of a Microgrid With a PV-Based Active Generator for Smart Grid Applications. IEEE Trans. Ind. Electron. 2011, 58, 4583-4592. [CrossRef]

16. Dragičević, T.; Vazquez, S.; Wheeler, P. Advanced Control Methods for Power Converters in Distributed Generation Systems and Microgrids. IEEE Trans. Ind. Electron. 2019, 66, 8866-8869. [CrossRef]

17. Kakigano, H.; Miura, Y.; Ise, T. Distribution Voltage Control for DC Microgrids Using Fuzzy Control and Gain-Scheduling Technique. IEEE Trans. Power Electron. 2013, 28, 2246-2258. [CrossRef]

18. Vu, T.V.; Paran, S.; Diaz, F.; Meyzani, T.E.; Edrington, C.S. Model predictive control for power control in islanded DC microgrids. In Proceedings of the IECON 2015-41st Annual Conference of the IEEE Industrial Electronics Society, Yokohama, Japan, 9-12 November 2015; pp. 1610-1615.

19. Vafamand, N.; Khooban, M.H.; Dragičević, T.; Blaabjerg, F. Networked Fuzzy Predictive Control of Power Buffers for Dynamic Stabilization of DC Microgrids. IEEE Trans. Ind. Electron. 2019, 66, 1356-1362. [CrossRef]

20. Kakigano, H.; Miura, Y.; Ise, T. Low-Voltage Bipolar-Type DC Microgrid for Super High Quality Distribution. IEEE Trans. Power Electron. 2010, 25, 3066-3075. [CrossRef]

21. Wang, J.; Jin, C.; Wang, P. A Uniform Control Strategy for the Interlinking Converter in Hierarchical Controlled Hybrid AC/DC Microgrids. IEEE Trans. Ind. Electron. 2018, 65, 6188-6197. [CrossRef]

22. Huang, J.; Zhang, X.; Shuai, Z.; Zhang, X.; Wang, P.; Koh, L.H.; Xiao, J.; Tong, X. Robust Circuit Parameters Design for the CLLC-Type DC Transformer in the Hybrid AC-DC Microgrid. IEEE Trans. Ind. Electron. 2019, 66, 1906-1918. [CrossRef]

23. Huang, J.; Guo, F.; Wen, C.; Yang, B.; Xiao, J. A Direct Power Control Strategy for AC/DC Converter Based on Best Switching State Approach. IEEE J. Emerg. Sel. Top. Power Electron. 2018, 6, 2273-2286. [CrossRef]

24. Keshavarzi, M.D.; Ali, M.H. A Novel Bidirectional DC-DC Converter for Dynamic Performance Enhancement of Hybrid AC/DC Microgrid. Electronics 2020, 9, 1653. [CrossRef]

25. Tabart, Q.; Vechiu, I.; Etxeberria, A.; Bacha, S. Hybrid Energy Storage System Microgrids Integration for Power Quality Improvement Using Four-Leg Three-Level NPC Inverter and Second-Order Sliding Mode Control. IEEE Trans. Ind. Electron. 2018, 65, 424-435. [CrossRef] 
26. Rodriguez, J.; Lai, J.-S.; Peng, F.Z. Multilevel inverters: A survey of topologies, controls, and applications. IEEE Trans. Ind. Electron. 2002, 49, 724-738. [CrossRef]

27. Barros, J.D.; Silva, J.F. Optimal Predictive Control of Three-Phase NPC Multilevel Converter for Power Quality Applications. IEEE Trans. Ind. Electron. 2008, 55, 3670-3681. [CrossRef]

28. Carpita, M.; Marchesoni, M.; Pellerin, M.; Moser, D. Multilevel Converter for Traction Applications: Small-Scale Prototype Tests Results. IEEE Trans. Ind. Electron. 2008, 55, 2203-2212. [CrossRef]

29. Barros, J.D.; Silva, J.F. Multilevel Optimal Predictive Dynamic Voltage Restorer. IEEE Trans. Ind. Electron. 2010, 57, 2747-2760. [CrossRef]

30. Nabae, A.; Takahashi, I.; Akagi, H. A New Neutral-Point-Clamped PWM Inverter. IEEE Trans. Industry Appl. 1981, IA-17, 518-523. [CrossRef]

31. Meynard, T.A.; Foch, H. Multi-level choppers for high voltage applications. EPE Eur. Power Electron. Drives Assoc. J. 1992, 2, 45-50. [CrossRef]

32. Marchesoni, M.; Mazzucchelli, M.; Tenconi, S. A non conventional power converter for plasma stabilization. In Proceedings of the 19th Annual IEEE Power Electronics Specialists Conference, Kyoto, Japan, 11-14 April 1988; Volume 1, pp. 122-129.

33. Leon, J.I.; Vazquez, S.; Sanchez, J.A.; Portillo, R.; Franquelo, L.G.; Carrasco, J.M.; Dominguez, E. Conventional Space-Vector Modulation Techniques Versus the Single-Phase Modulator for Multilevel Converters. IEEE Trans. Ind. Electron. 2010, 57, 2473-2482. [CrossRef]

34. Barros, J.D.; Silva, J.F.; Jesus, É.G. Fast-Predictive Optimal Control of NPC Multilevel Converters. IEEE Trans. Ind. Electron. 2013, 60, 619-627. [CrossRef]

35. Monge, S.B.; Griñó, R.; Apruzzese, J.N.; Bordonau, J. Decoupled DC-Link Capacitor Voltage Control of DC-AC Multilevel Multileg Converters. IEEE Trans. Ind. Electron. 2016, 63, 1344-1349. [CrossRef]

36. Babaei, E. A Cascade Multilevel Converter Topology with Reduced Number of Switches. IEEE Trans. Power Electron. 2008, 23, 2657-2664. [CrossRef]

37. Rodriguez, J.; Cortes, P. Predictive Control of Power Converters and Electrical Drives; Wiley-IEEE Press: Piscataway, NJ, USA, 2012.

38. Shieh, H.J.; Shyu, K.K. Nonlinear sliding-mode torque control with adaptive backstepping approach for induction motor drive. IEEE Trans. Ind. Electron. 1999, 46, 380-389. [CrossRef]

39. Martin, A.D.; Cano, J.M.; Silva, J.F.; Vázquez, J.R. Backstepping Control of Smart Grid-Connected Distributed Photovoltaic Power Supplies for Telecom Equipment. IEEE Trans. Energy Convers. 2015, 30, 1496-1504. [CrossRef]

40. Flores, J.L.; Rodríguez, C.G.; Ramírez, H.S.; Cárdenas, O.R. Robust Backstepping Tracking Controller for Low-Speed PMSM Positioning System: Design, Analysis, and Implementation. IEEE Trans. Ind. Inform. 2015, 11, 1130-1141. [CrossRef]

41. Shah, A.A.; Han, X.; Armghan, H.; Almani, A.A. A Nonlinear Integral Backstepping Controller to Regulate the Voltage and Frequency of an Islanded Microgrid Inverter. Electronics 2021, 10, 660. [CrossRef]

42. Khan, R.; Khan, L.; Ullah, S.; Sami, I.; Ro, J.-S. Backstepping Based Super-Twisting Sliding Mode MPPT Control with Differential Flatness Oriented Observer Design for Photovoltaic System. Electronics 2020, 9, 1543. [CrossRef]

43. Ud Din, W.; Zeb, K.; Ishfaq, M.; Ul Islam, S.; Khan, I.; Kim, H.J. Control of Internal Dynamics of Grid-Connected Modular Multilevel Converter Using an Integral Backstepping Controller. Electronics 2019, 8, 456. [CrossRef]

44. Krstic, M.; Kanellakopoulos, I.; Kokotovic, P.V. Nonlinear and Adaptive Control Design; Wiley Series: Hoboken, NJ, USA, 1995. 